\title{
La lógica de los sistemas hidráulicos del Valle de Lecrín y su justificación histórica y territorial: el caso de las acequias de Cozvíjar, Dúrcal y Nigüelas
}

\author{
José Ramón Guzmán Álvarez \\ ramonguzmanalvarez@gmail.com
}

\begin{abstract}
Resumen. El Valle de Lecrín es una comarca histórica de la provincia de Granada localizada en la vertiente meridional de Sierra Nevada al oeste de la Alpujarra, con la que comparte similitudes geográficas e históricas. Sus sistemas de regadío entran dentro de la categoría de regadíos históricos de la montaña andaluza que por sus características se adaptan con dificultad a los requerimientos de la agricultura contemporánea. En este trabajo se estudian cuatro de los sistemas hidráulicos del Valle de Lecrín pertenecientes a los pueblos de Cozvíjar, Dúrcal y Nigüelas. Al igual que otras zonas del sureste español que quedaron marcadas por el proceso repoblador derivado de la expulsión de los moriscos de finales del siglo XVII, es posible marcar algunos hitos de la evolución de los sistemas hidráulicos del Valle de Lecrín y, en general, del paisaje rural, indagación que se ha nutrido también de la revisión de las fuentes árabes anteriores. De manera complementaria, el estudio territorial de detalle, junto con la revisión de los trabajos arqueológicos llevados a cabo en esta área, ofrece información adicional que permite ampliar el alcance de las hipótesis interpretativas sobre la evolución de estos sistemas de regadíos. Como resultado de este análisis se plantea la hipótesis de que algunos de los sistemas hidráulicos de regadío del Valle de Lecrín tienen su origen en la explotación minera hidráulica de sedimentos auríferos.
\end{abstract}

Palabras clave: Regadíos, Minería aurífera, Origen de los regadíos

\begin{abstract}
Historical significance and evolution of irrigation systems in the Lecrin Valley (south of Granada): four cases studies in Cozvijar, Dúrcal, El Padul and Nigüelas. The Lecrin Valley is a natural and historical region in the province of Granada (Andalucia, south of Spain), located near the Alpujarra region, on the south-west slopes of the Sierra Nevada. The Lecrin Valley is characterised by its historical Mediterranean mountainareas irrigation systems. The purpose of this study was to inquire into the evolution of four of these irrigation systems in the villages of Cozvijar, Dúrcal, El Padul and Nigüelas. Most of the historical documentation came from the period of time from the conquest of Granada (1491) to the expulsion of the moriscos (1571). Sources as the Books of Habices and the Books of Apeo and Repartimiento give information about the 16th-century landscapes, use of territory or the irrigation network, and even led to a partial reconstruction of Nasrid times. It is possible as well to search for more details about past landscape evolution consulting other sources as archaeological inquiries and through a field study approach supported by GIS based information. As a result, the hypothesis of a roman origin of some of these channels is proposed, with the function of supplying water to wash the alluvial deposits of gold mines.
\end{abstract}

Keywords: Irrigation systems, History of irrigation, Roman gold-mining.

\section{Introducción}

El Valle de Lecrín es una comarca natural situada en la provincia de Granada al suroeste de Sierra Nevada. Desde el punto de vista paisajístico destaca su núcleo central, una fosa tectónica en donde convergen diferentes ríos y barrancos tributarios del río Guadalfeo que han excavado cauces en general profundos y angostos. El Valle de Lecrín está delimitado en su práctica integridad por un conjunto de relieves montañosos de gran personalidad: al norte, las estribaciones occidentales de Sierra Nevada, con el cerro del Caballo $(3.011 \mathrm{~m})$ como telón de fondo, al sur, la sierra de Albuñuelas y las sierras de los Guájares y Sierra Chinchirina, que recorre los antiguos términos de Saleres, Restábal, Pinos e Ízbor, ramifi- 
caciones orientales de la Sierra de la Almijara. Estas sierras forman una barrera que ha dificultado históricamente el tránsito natural entre Granada y la costa del Mediterráneo, habiendo sido el Valle de Lecrín un paso obligado hacia el litoral y la Alpujarra dada su situación intermedia.

Las sierras del Valle de Lecrín determinan su paisaje y las condiciones de su hábitat. Crean un refugio climático y son el origen de los ríos y fuentes que nacen en las zonas de contacto entre materiales geológicos muy contrastados. Los perfiles de la fosa central están bien delimitados por la presencia de líneas de fallas normales paralelas de dirección Este-Oeste, situadas tanto en el borde meridional como en el septentrional. Los niveles de depósitos de sedimentos de diferentes edades geológicas, origen y granulometría (arcillas, limos, margas, arenas, brechas y conglomerados heterométricos, abanicos aluviales, travertinos) llegan a tener espesores de centenares de metros, destacando la presencia de glacis cuaternarios formados con anterioridad al encajamiento de la red fluvial. Destaca también la formación de niveles de calcarenitas del Tortoniense que han dado lugar a un relieve alomado y acolinado. Tras la formación del glacis cuaternario, la región sufrió un proceso de levantamientos y juego de fallas que aún continúa en la actualidad.

Los depósitos de la cuenca de Padul-Nigüelas, al norte, localizada en los actuales términos municipales de El Padul, Villamena (formado por la unión de los pueblos de Cozvíjar y Cónchar), Dúrcal y Nigüelas, descansan sobre el basamento de la Zona Interna de la Cordillera Béticas (rocas metamórficas triásicas del Manto Alpujárride). Las rocas más antiguas que rellenan esta cuenca son conglomerados del Mioceno Superior y calcarenitas. Durante el Plioceno y Pleistoceno se generaron varios niveles de sedimentos aluviales: en la base se sitúa la denominada Formación Roja, visible en las proximidades del río Dúrcal; sobre ellos se sitúa la Formación de Nigüelas, que se presenta sobre todo en el sector meridional. Ambas formaciones comprenden sedimentos no cementados y poco compactados de diferente granulometría, predominando las gravas y arenas con arcillas rojizas (Sáenz de Galdeano et al, 2001; Alfaro et al, 2001).

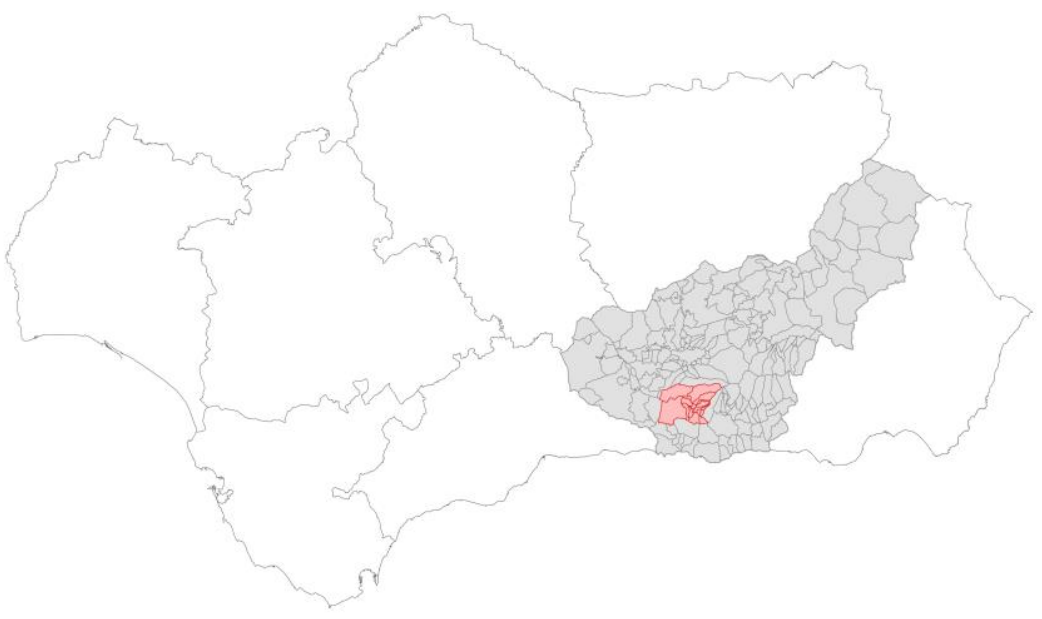

Fig. 1. Localización del Valle de Lecrín. 
El paisaje actual, en definitiva, ofrece un conjunto de formas de relieve muy contrastadas. Sierra Nevada, al norte, con una primera orla de calizas y dolomías que da lugar a unos relieves muy abruptos que han constituido un impedimento insoslayable para su conversión en terreno cultivado; entre las cotas 1250 y 2000 metros, aproximadamente, y tras esta primera franja, comienzan los materiales paleozoicos de Sierra Nevada (filitas, micaesquistos y otras rocas) que originan relieves alomados, suaves, que han permitido el laboreo. Al sur, el conjunto de las sierras de los Guájares y Chinchirina está delimitado por una serie de fallas con saltos de hasta 1.000 metros que individualizan los rellenos de la fosa, la cual presenta varios niveles de materiales geológicos. Varias alineaciones paralelas de cerros de calizas y dolomías alpujárrides se elevan en torno a la fosa en dirección este -oeste destacando sobre los relieves depresionales, llanos o con ligera inclinación, de la fosa propiamente dicha, de las superficies de glacis y de la Formación Nigüelas.

Los tres ríos del Valle de Lecrín, Dúrcal, Torrente y el río Santo de Albuñuelas-SaleresRestábal, han trazado su cauce sobre este relieve en un proceso de encajamiento todavía activo debido al alzamiento de la región. Este encajamiento es especialmente patente en los ríos Torrente y Dúrcal entre las cotas 900 y 1.200 m, al atravesar las calizas y dolomías de la orla alpujárride de Sierra Nevada siguiendo un trazado sinuoso con ásperas y escarpadas vertientes. Superado el frente de fallas, el río Dúrcal se dirige hacia el sur encajado en un profundo y recto barranco excavado en los conglomerados, brechas y otros depósitos aluviales, hasta que se ve obligado a tomar la dirección sureste - este para franquear los relieves alpujárrides de la sierra de Cónchar. El río Torrente recorre un trayecto más corto y menos dificultoso al atravesar una menor sección de las calizas y dolomías alpujárrides y no enfrentarse a ningún espolón serrano adicional.

El Valle de Lecrín fue estudiado en profundidad por Francisco Villegas Molina en un estudio geográfico publicado en 1972 (Villegas Molina, 1972). En dicho trabajo se incluye una recopilación detallada de los sistemas de regadío y de la forma de distribución y uso del agua que permite tener una referencia previa a la crisis de la agricultura tradicional.

Desde los años setenta del siglo XX estos sistemas de regadío han continuado su evolución, con distintas ampliaciones y, especialmente, con modificaciones en el origen del agua, si bien la red de trazado básico aún se mantiene. Los usos y normas de regulación también han variado, adaptándose al proceso de cambio socioeconómico tan intenso que se ha producido en los últimos decenios, que se ha manifestado de forma especialmente patente en el Valle de Lecrín debido al envejecimiento de la población y a la dificultad de acomodar una estructura del regadío y un parcelario muy fragmentado a las exigencias actuales.

En esta comunicación se presenta una aproximación a estos regadíos desde el punto de vista de su evolución histórica, centrada en los sistemas hidráulicos del sector septentrional que toman el agua de los ríos Dúrcal y Torrente.

\section{Metodología}

El trabajo parte del estudio de la trama territorial de los sistemas hidráulicos, tanto in situ como utilizando herramientas de información geográfica. Para ello se ha creado un Sistema de Información Geográfica que, además de integrar distinto tipo de información cartográfica territorial, incorpora las fotografías aéreas georreferenciadas de la zona de los 
años 1956, 1977, 1997 y 2008, apoyo imprescindible para estudiar la evolución histórica reciente de este territorio. También se han integrado las fuentes cartográficas: la cartografía histórica (mapas 1:50.000 del Servicio Cartográfico Nacional de las décadas de 1920 y 1930) y los mapas cartográficos recientes a diferente escala territorial $(1: 10.000,1: 25.000$, 1:50.000). Aparte de su valor intrínseco, esta cartografía es de gran utilidad para los estudios relacionados con la toponimia y para determinar la traza de las vías de comunicación históricas.

Paralelamente se han realizado visitas de campo a la zona de estudio y se ha profundizado en su conocimiento a través de la recopilación bibliográfica de publicaciones y otros trabajos que tengan como referencia al Valle de Lecrín o que aporten información sobre su contexto histórico y geográfico.

Por último, se han estudiado documentos históricos originales, en especial de los siglos XV y XVI, época en la que se originó una gran cantidad de documentación ligada a la conquista del antiguo Reino de Granada por la Corona de Castilla. La información previa al siglo XV es mucho más escasa, lo que limita el conocimiento sobre el territorio y su uso y ocupación durante la época nazarí y anteriores (Trillo San José, 1994, 2004). Sin embargo, fuentes posteriores como los Libros de Habices (varias fechas entre 1501 y finales del siglo XVI; los de 1501 se han trabajado sobre el original, A.G.S., C.M.C., $1^{\text {a }}$ época, leg. 131; el resto de Libros de Habices consultados han sido transcritos y editados por Padilla Mellado, 2010) y los Libros de Apeo y Repartimiento hacen posible elaborar reconstrucciones, aunque fragmentadas, de la realidad territorial anterior. De los pueblos estudiados en esta comunicación, tan sólo el Libro de Apeo y Repartimiento de Nigüelas (1572 para el Libro de Apeo y 1611 y una fecha anterior para el Libro de Repartimiento) está publicado (Ferrer, 2000), habiéndose procedido para este trabajo a la transcripción de los Libros de Cozvíjar (1592), Dúrcal (para el Libro de Apeo 1572 y para el Libro de Repartimiento una fecha posterior, en torno a 1590) y Cónchar (1593) conservados en el Archivo Histórico Provincial de Granada (Signaturas 6677 y 6678 para Dúrcal, 6692 para Cónchar y 6693 para Cozvijar)'

\section{Caracterización de las acequias de Dúrcal, Nigüelas y Cozvíjar}

Si bien existen algunos otros sistemas hidráulicos de menor entidad (algunos de ellas de carácter histórico, sin uso actual), son cinco las principales redes de acequias del sector septentrional del Valle de Lecrín (correspondiente a los pueblos de El Padul, Cozvíjar, Cónchar, Dúrcal y Nigüelas): la acequia de Nigüelas-Dúrcal, la acequia de Márgena, la acequia de Cózvíjar-Marchena, la acequia de los Llanos y la acequia Real de Cónchar (esta última acequia, que toma el agua del río de la Laguna, no es objeto de esta comunicación).

Estos pueblos son anteriores a la conquista castellana, como sabemos tanto por los Libros de Habices de 1501 como por la bula de erección del arzobispado de Granada de 1505:

\footnotetext{
1 Hay una transcripción del Libro de Apeo y Repartimiento de Dúrcal, realizada de forma colectiva en la Biblioteca de Dúrcal, que puede ser consultado en la web http://www.adurcal.com/enlaces/mancomunidad Lguia/apeo/apeodurcal.htm. Por otro lado, García Pérez (2013a, b) ha estudiado recientemente los paisajes históricos del área norte del Valle de Lecrín de la época nazarí a la conquista castellana, de acuerdo con las referencias recogidas en Malpica Cuello (2014).
} 
In ecclesia parochiali Sancta Mariae loci de Padul cum suis annexis de Concha, Coxbixar, Durcal et Ni-gueles, locorum Granatensis diocesis, traia benefitia simplitia seruitoria et tres sacristias. (Padilla Mella-do, 2010)

Tres de estas acequias toman el agua del río Dúrcal, cuando aún está encajado en los materiales calizos-dolomíticos de Sierra Nevada a una cota de, aproximadamente, 800 metros. $\mathrm{El}$ agua procede de tres presas escalonadas (conocidas como "las tres presillas") con la siguiente disposición: primero toma la acequia de Márgena, que riega Dúrcal (lado izquierdo); después, la acequia de Cozvíjar-Marchena (parte derecha) y, más abajo, la acequia de los Llanos (parte derecha). Es de destacar que el trazado y el área regable de la acequia de Los Llanos son superiores en cota a los de la acequia de Cozvijar-Marchena, pese a que su cota de toma es inferior. Esto es posible porque los cauces de ambas acequias se cruzan al inicio de sus recorridos. El derecho histórico al uso del agua es coherente con la disposición de las tomas de agua, con la preferencia de los riegos del área regable de Márgena sobre la de Cozvijar-Marchen, y de ésta sobre la de Los Llanos.

La acequia de Márgena y la de Cozvíjar-Marchena aparecen recogidas en los libros de Apeo y Repartimiento de Cozvíjar y Dúrcal y ambas reciben la denominación de "acequia real".

En el Libro de Repartimiento de Cozvíjar se menciona en múltiples ocasiones "la acequia que riega el lugar", haciéndose referencia también a acequias que reciben el nombre de distintos pagos, que pueden ser identificadas como las acequias secundarias de este sistema.

En el Libro de Apeo de Dúrcal (1572) se describen los sistemas de regadío de Dúrcal, que incluyen tres acequias: la de Cozvíjar-Marchena, la de Márgena y la que viene de Nigüelas:
/ fol 9r/ En el dicho lugary su termino ay dos acequias principales que son suyas en propiedad la una se saca del río del Torrente, la otra del río de Márgena, e ai otra acequia que se toma del río de Margena que ba a Cosbijar e goza de ella Durcal la tercera parte, con la agua de las dichas acequias se riegan todas las eredades del dicho lugar, e ai agua bastante para ello,

En el Libro de Repartimiento de Dúrcal, elaborada con posterioridad al Libro de Apeo, se menciona en repetidas ocasiones que la acequia de Cozvíjar-Marchena riega Cozvíjar y el pago de Marchena (situado al norte del pueblo de Cozvíjar), dando agua asimismo al término de El Padul, que comparte tierras en este pago.
I fol $50 \mathrm{r} /$ Una haza de dos fanegas de sembradura cerca del almadraba do hacen teja linde tierras de Aboay vezino de Niguelas y ba por la cabezada del acequia que ba a Cuxbijar, y por la parte baja con el acequia que ba a Malchena con una almadraba, que esta dentro en ella do se bace la dicha teja y ladrillo

La acequia de Cozvijar-Marchena divide el agua en un partidor al que se hace mención en el Libro de Repartimiento de Dúrcal y que todavía está en uso (así se deduce del emplazamiento que se recoge en el Libro de Repartimiento de Dúrcal). El caudal se divide entre las dos, la de Marchena y la de Cozvíjar que, con posterioridad, se van subdividiendo en ramales que se adaptan cuidadosamente a la topografía del terreno para regar la máxima superficie posible.

El trazado de la acequia de Cozvíjar-Marchena presenta una trayectoria recta desde la salida del río de la Sierra (contacto de falla entre los materiales sedimentarios y los alpujárrides) hasta el partidor. El recorrido es técnicamente difícil desde la presa del río hasta la sa- 
lida del barranco, a una cota aproximada de $775 \mathrm{~m}$, con minas y excavaciones en roca en su tramo inicial y ajustado a la gran inclinación de talud del barranco en su tramo medio; una vez superado el encajamiento del barranco (en las proximidades de la antigua carretera nacional N-323) la acequia discurre con facilidad hasta el partidor, excavada sobre los depósitos de arcillas rojas y cantos rodados que han dado lugar a un tipo de suelo rojo mediterráneo muy característico. La zona regable se sitúa entre las cotas 775 y 730 metros hacia el oeste (cauce del río la Laguna) y hasta los $680 \mathrm{~m}$ al este (cauce del río Dúrcal). La traza principal de la acequia, tal y como se puede comprobar en el plano de Cozvíjar realizado para el Catastro del Marqúes de la Ensenada (Malpica Cuello, 2014) pasa por el interior del pueblo, cortándolo en dirección norte-sur.

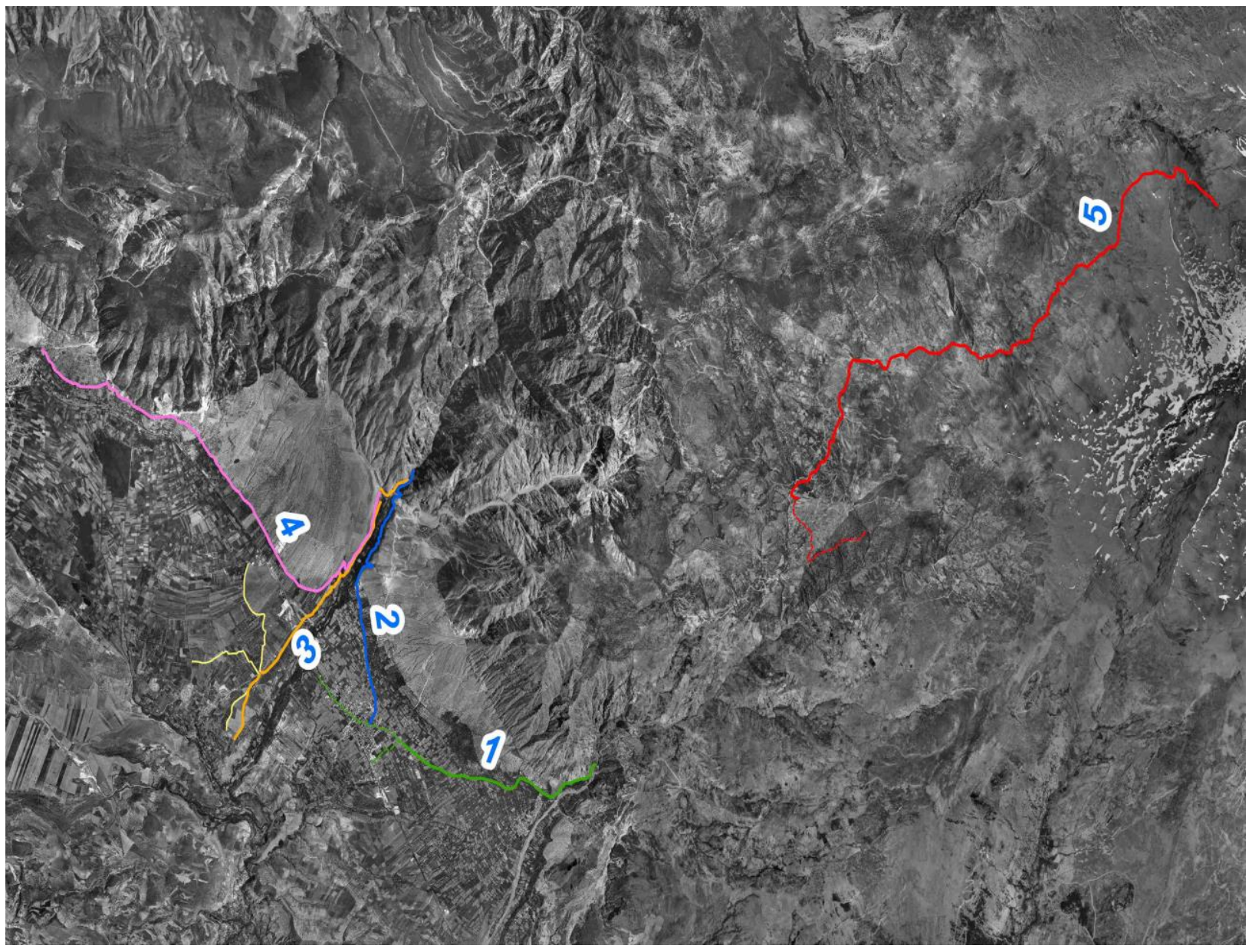

Fig. 2. Acequias del sector septentrional del Valle de Lecrín. Conducciones principales. 1. Acequia de Nigüelas-Dúrcal. 2. Acequia de Márgena. 3. Acequia de Cozvíjar-Marchena. 4. Acequia de Los Llanos. 5. Acequia de los Hechos.

La acequia de Márgena toma su nombre de un antiguo barrio de Dúrcal situado al este del río (el de pago de Marchena, topónimo con el que a veces se confunde, se localiza al oeste, en la otra orilla). Quedan aún los restos de la torre de alquería del lugar (Malpica Cuello, 1996; Padilla y Espinar, 2007; Pedregosa Megías, 2011). En sus alrededores es posible encontrar numerosos restos cerámicos de tipología nazarí. Este barrio ya amenazaba ruina en abril de 1572, cuando el Licenciando Jusepe Machuca realizó el apeo y deslinde de los bie- 
nes de los moriscos y quedó la constancia escrita del testimonio de Juan de la Torre, nuevo poblador del lugar:

Ifol 100 r/ Otrosi digo, que muchas casas ai en el varrio de Marjena del dicho Lugar que estan señala-das á vecinos del dicho Lugar de Durcal los quales no viven ni quieren vivir en el dicho Lugar de Marjena y por esta causa las dichas casas se pierden por estar inavitadas y desiertas á vuestra Alteza pido y suplico mande dar licencia para que el que viviere en el dicho Lugar de Marjena pueda aprovecharse de las dichas casas, y dallas a quien en ellas viva con que esten reparadas.

Esta acequia alcanza el plano inclinado cubierto por los materiales de la Formación Nigüelas a una cota aproximada de $796 \mathrm{~m}$, dirigiéndose en dirección sureste al pueblo de Dúrcal con un trazado muy suave, adaptado a las curvas de nivel $(0,47 \%$ de pendiente en 1.600 metros de recorrido hasta el centro de la población) para regar la superficie de vega que queda en su mayor parte al sur del caserío. La zona regable se extiende hasta la cota 775 metros, aproximadamente, entreverada por algunas elevaciones a donde no es posible que llegue el agua. Esta acequia cruza el pueblo de Dúrcal en dirección noroeste-sureste.

La acequia de Los Llanos no aparece recogida en los Libros de Repartimiento. García Pérez (2011) la reconoce como una acequia posterior, de entre el siglo XVII y XVIII. Sale del encajamiento del barranco del río Dúrcal a una cota de unos $785 \mathrm{~m}$ y discurre por un trazado de fácil ejecución en dirección este-oeste que cuenta con una longitud de más de tres kilómetros regando unos pagos situados por encima de la zona regable de Marchena, que se prolongan en el término de El Padul.

La acequia de Nigüelas-Dúrcal toma sus aguas del río Torrente en una presa situada a 980 m, en el umbral de Sierra Nevada. Debe superar un primer tramo de 500 metros de materiales calizos dolomíticos alpujárrides y un segundo de una longitud similar que debe superar un banco de gran espesor de conglomerados. Ambos recorridos han exigido obras de ingeniería complicada. Las calizas y dolomías se salvan a través de túneles y trincheras; destacando "Las Rajas", dos trincheras que han hendido la roca abriendo un pasillo de unos $80 \mathrm{~cm}$ de ancho y una altura que superar 5 metros por donde discurre la acequia y otro pasillo paralelo al anterior correspondiente al antiguo camino de andén. El paso por los conglomerados se ha resuelto a través de un cauce descubierto que bordea un enorme talud. Una vez superada la falla $(960 \mathrm{~m})$, la acequia se acomoda con facilidad al plano inclinado de los materiales de la formación Nigüelas, con una traza de resolución sencilla mediante una simple excavación. La conducción principal presenta una orientación suroeste, concluyendo poco antes de llegar al caserío de Dúrcal. El recorrido de la acequia principal presenta una pendiente media del 7,5\% entre la cota correspondiente al contacto de los materiales sedimentarios con la Sierra (aproximadamente $952 \mathrm{~m}$ ) y el punto final de la conducción principal actual (aproxm. $830 \mathrm{~m}$ ) para un recorrido de 1.600 metros, un trazado que no se adapta a la topografía en aras a optimizar la superficie potencialmente regable. La acequia cruza por el centro del pueblo de Nigüelas en dirección norte-sur.

fol $5 b$ En el dicho lugar y su término ay dos asequias de agua con que se rriegan todas las heredades del e de que beve el pueblo, tomase del arroyo que llaman el torrente, que baxa d ela Sierra nebada en termino de niguelas, en esta manera que del dicho torrente se saca una hazequia con su presa y biene hasta cera del dicho lugar de niguelas que será un quartod e legua, e alli se parte la dicha asequia en dos partes, la una de ella ba a el lugar e termino de Nigueles y la otra al termino de el lugar de Durcal, e la que biene a nigueles se parte en tres ramales e asequias 
Este sistema hidráulico presenta varias particularidadades. De la conducción principal Nigüelas-Dúrcal nacen varios brazales que riegan parcelas situadas en su margen derecha; de la información aportada por el Libro de Repartimiento se infiere que algunos de ellos se trazaron con posterioridad a la colonización castellana. Estos brazales, al contrario que la conducción principal, presentan un trazado suave, acomodado al terreno, propio de un diseño cuya finalidad sea aportar agua a la máxima superficie posible.

Una segunda particularidad es que este sistema hidráulico está constituido por dos subsistemas: el de la acequia Nigüelas-Dúrcal y el de una segunda acequia principal que riega los términos de Acequias y Mondújar, situados en la orilla opuesta del río Torrente. El agua represada en un único punto se divide en tres partes en un partidor situado junto al río, a unos 150 metros de la presa. Una tercera parte del caudal se encauza por una acequia que cruza de forma subterrána el río Torrente y que se prolonga en la acequia de AcequiasNigüelas. Los dos módulos restantes se encauzan a través de la acequia principal hasta un segundo partidor situado en la entrada del pueblo de Nigüelas, que divide el agua en dos partes: una para el acequia que fecunda pagos de Dúrcal y otra para el acequia que riega los pagos de Nigüelas, recibiendo cada uno de estos términos, por consiguiente, una tercera parte del agua de la presa común.

Una tercera particularidad del sistema hidráulico es que está ligado en su cabecera a una acequia que discurre a una cota muy superior: la denominada Acequia de Los Hechos del Marqués de Mondéjar o de la Alfaguara. Esta acequia toma el agua en las fuentes del río Dúrcal bajo la cima del Cerro del Caballo a 2.800 metros y tras un recorrido de unos 9,5 $\mathrm{km}$ vierte el agua en un barranco que conduce el agua al río Torrente. La finalidad de esta acequia de montaña es derivar el agua de la cuenca del río Dúrcal a la del Torrente; este último tiene un régimen de caudal mucho más estacional, derivado de su menor recorrido y de que sus fuentes se localizan en la falda meridional de Sierra Nevada. Esta acequia de montaña amplió su recorrido en la década de 1990 con el objetivo de alimentar el canal de abastecimiento de la central hidroeléctrica que se instaló en Nigüelas: con ello se amplió el uso del agua, sin que supusiera menoscabo para el regadío inferior.

La acequia de los Hechos discurre por las tierras que se han cultivado históricamente en la Sierra Nevada de Dúrcal (entre unas cotas de 1.650 a 2.000 metros). En la actualidad estos terrenos no se riegan, pero por el Libro de Repartimiento sabemos que ya en 1603 existía una acequia de la dehesa (se refiere a la dehesa del Marqués de Mondéjar, localizada sobre las tierras de cultivo de la sierra de Dúrcal) y una acequia vieja que pueden relacionarse con la actual acequia de los Hechos:

\section{I fol $517 v /$ Anton Portillo tiene suerte quinta y a alinda con Bartolome de la Puerta por la parte de abaxo y por la parte alta con el acequia de la dehesa y del acequia bieja.}

En este repartimiento se alude a que eran tierras de secano de la sierra, de lo que se deduce que estas acequias no tenían uso en esa fecha. Sin embargo, conocemos por el Libro de Apeo (redactado en 1573) que entre los bienes que declaraba poseer el cristiano viejo Diego de Zaragoza había tierras de riego en la Sierra:

41 r Otro pedazo de tierra en la Sierra del Lugar, que es la octava parte de una haza que es la baza que se llama de Acerrebe que es parte de riego, y parte de secano y vendioseme banega y media de sembradura, todo lo que le pertenece al reconciliado 
El hecho de que fueran tierras de riego también es apoyado por la circunstancia de que en las tierras vecinas de Sierra Nevada de Nigüelas había tierras y acequias de riego a una cota similar a la de los terrenos de Dúrcal.

\section{/fol 209/ "Una haça de rriego que dicen el Posterguelo, linde con tierras del Licenciado Narvaez, sirve de mojón una acequia que corta derecho desde el peñón del posterguelo basta las peñas arriba, va a descabeçar a la mojonera de Lanjaron..."}

Esta zona en concreto es localizable en la cartografía 1:25.000 en donde se conserva el topónimo "El Posteruelo" junto a un fuente denominada Mailópez (que corresponde con uno de los nombres que se citan en el Libro de Repartimiento de Nigüelas) a una cota entre 2.000 y 2.050 metros.

De los documentos del siglo XVI (Libros de Habices y Libros de Apeo y Repartimiento) se deduce que las acequias de Cozvíjar-Marchena, de Márjena y de Nigüelas-Dúrcal eran anteriores a la conquista castellana. Todas estas acequias riegan más de un término excepto la de Margéna (que solo aporta agua a Dúrcal): la de Cozvíjar-Marchena a los de Cozvíjar, Dúrcal y El Padul; la de Nigüelas-Dúrcal, a ambos pueblos más Acequias y Mondújar; la de los Llanos (posterior al siglo XVII) a Dúrcal y El Padul.

\section{Propuesta de interpretación de las acequias de Dúrcal, Nigüelas y Cozvíjar.}

Una vez descritos los sistemas hidráulicos, es conveniente subrayar algunos rasgos peculiares que se extraen de su análisis conjunto:

1.- La disposición de los trazados de las acequias responde a patrones distintos. En el lado derecho del río Dúrcal la acequia de Cozvíjar-Marchena tiene un trazado norte-sur y no comienza a regar hasta el partidor, a $1,5 \mathrm{~km}$ de la salida del barranco del río, ya en las proximidades del caserío de Cozvijar, en donde se deriva un ramal para regar el pago de Marchena. En contraposición, la acequia de los Llanos presenta una orientación este-oeste, optimizando desde su salida del barranco la superficie regable, con una orientación y trazado suave, coincidente con la disposición de las curvas de nivel.

En el lado izquierdo, la acequia de Márgena y la acequia de Nigüelas-Dúrcal presentan una orientación opuesta (noroeste-sureste y noreste-suroeste). La acequia de Nigüelas-Dúrcal muestra, además, otra interesante particularidad: su trazado discurre por la orilla del camino viejo que une ambas poblaciones. La acequia muere antes de llegar al caserío, en un punto indiferenciado del territorio; sin embargo, el camino continúa, manteniendo la misma orientación y pendiente, prolongándose después en la calle Darrón (nombre de uno de los antiguos pagos de Dúrcal) y, tras cruzar en diagonal la población, en el camino antiguo del pueblo hacia Granada, que bajaba al río por una cuesta suave y lo cruzaba por un puente que aún se conserva. Esta disposición y la continuidad topográfica y geológica plantea un interrogante: ¿por qué la acequia de Nigüelas-Dúrcal no continúa su recorrido en paralelo al viario? Si así lo hiciera, su traza convergería con el de la acequia de Márgina en un punto situado en las proximidades del centro de la población.

El trazado de estas acequias no responde al mismo modelo. Mientras que la acequia de Nigüelas-Dúrcal tiene una pendiente considerable (7,5\%), cortando las curvas de nivel sin amoldarse a ellas, con una aparente despreocupación por la pérdida de cota, la de Márgena, se acomoda al terreno y recorre muy suavemente (pendiente del $0,47 \%$ ) la distancia 
que ha de recorrer por el glacis, tras haber superado el barranco del río. El diseño de la primera (Nigüelas-Dúrcal), en definitiva, parece responder a la intención de llegar al final del recorrido sin dilaciones, mientras que en el segundo caso (Márgena) el trazado es el propio de un diseño hidráulico concebido para optimizar la superficie regable.

2.- Añadidos posteriores han completado la red de acequias para aumentar la superficie regable más allá del diseño o diseños iniciales de los sistemas de regadío. En el caso de la acequia de Nigüelas-Dúrcal, brazales situados al norte del recorrido principal riegan pagos á donde el agua no llegaría inicialmente (brazal de la acequia del secano y brazal del Huerto de López, en el pago del Romeral del Zahor). La acequia de los Llanos, por su parte, riega terrenos de características agrológicas similares a los que riega la acequia de CozvíjarMarchena pero que eran de secano en el siglo XVII (el Romeral de Marchena).

Es importante destacar que el riego de estos pagos, tanto en un caso como en el otro, podría haberse resuelto con facilidad con un diseño inicial distinto puesto que el recorrido de las acequias no presenta restricciones ni dificultades técnicas notorias de tipo topográfico o en base a las características del terreno. Las nuevas acequias y brazales ampliaron el área irrigada a terrenos de la misma calidad agrológica que los antiguos pagos de riego que encontraron los repobladores castellanos pero que formaron parte del diseño inicial del regadío.

3.- El sistema hidráulico de Nigüelas-Dúrcal debió integrar al de Acequias-Mondújar (que debía ser independiente, tomando agua de una presa propia en el río Torrente) en una fecha indeterminada pero posterior al siglo XVII. Así se infiere del Libro de Repartimiento de Nigüelas en donde se menciona que con esta acequia se riegan pagos de Dúrcal y Nigüelas, y que el agua se divide en un partidor cuyo emplazamiento coincide con el primero de los dos actuales.

¿Es posible proponer una interpretación de conjunto para las peculiaridades e interrogantes de estos sistemas hidráulicos? Antes de ello, es preciso entrar en el detalle de algunas características geomorfológicas de la zona, en concreto de las márgenes del río Dúrcal. Tanto en la vertiente derecha como en la izquierda es posible localizar algunas singularidades. En concreto, junto al caserío de Cozvíjar y de Dúrcal se puede apreciar una discontinuidad topográfica en las márgenes del barranco del río Dúrcal. Como es apreciable en las curvas de nivel y en la inspección visual sobre el terreno, los taludes aparecen desmontadas, como si se hubiese producido un deslizamiento o un fenómeno erosivo de gran magnitud. En ambos casos, la discontinuidad se aprecia mejor en la disposición de las curvas de nivel que en el propio terreno en donde queda enmascarada por el abancalamiento.

Es de remarcar que ambas zonas de desmonte se localizan junto a los puntos que aportan singularidad a los sistemas hidráulicos estudiados. La de Cozvijar, en el extremo de la alineación recta de la acequia en el borde del barranco. La de Dúrcal, en la prolongación natural de la acequia de Nigüelas-Dúrcal, coincidente con el viario histórico, llegando hasta el mismo cauce del río.

Este tipo de conformación geomorfológica tiene elementos en común con otros paisajes singulares que se han interpretado como antiguas explotaciones auríferas hidráulicas romanas, cuya presencia en el entorno de la Alhambra en el Cerro del Sol ha sido recientemente estudiada por García Pulido (2013), a unos $20 \mathrm{~km}$ del área de estudio. 
La naturaleza geológica de los depósitos de Dúrcal y Cozvíjar guarda equivalencia con los materiales explotados en la cuenca del Genil en Granada: sedimentos detríticos gruesos ligados a depósitos aluviales procedentes de Sierra Nevada: cantos rodados y conglomerados con cantor heterométricos de rocas metamórficas (micaesquistos, cuarcitas, gnesis, serpentinas, etc.).

Sabemos que paisajes mineros como los de las Médulas o el Cerro del Sol en Granada dan lugar a una serie de elementos característicos como desmontes o vaciados mineros, canales de minado, galerías o pozos de explotación. Planteamos como hipótesis que las discontinuidades topográficas de Dúrcal y Cozvíjar sean la consecuencia de explotaciones de tipo ruina montium, aunque habiendo experimentado una transformación intensa posterior para su uso agrario (en una suerte de restauración minera). No se han localizado en estos dos emplazamientos galerías de agua o pozos, pero ello puede ser debido a la relativamente escasa entidad superficial y volumétrica de la explotación y a la transformación posterior del terreno al instalar las terrazas agrícolas. De hecho, el material de las posibles "murias" o acumulaciones de cantos de gran dimensión procedentes de lavado se pudo reutilizar en los balates (paratas o paredes) de las terrazas, como se propone para la zona del Cerro del Sol.

Hay otras evidencias que apoyan esta hipótesis de trabajo. El trazado de la acequia de Nigüelas-Dúrcal en su primer tramo (trincheras, túneles, anchura del cauce) es similar al de las conducciones que llevaban el agua a la explotación minera de Las Médulas, en León, y que se pueden localizar en la comarca de La Cabrera en León.

El nombre de Marchena, como se ha puesto de manifiesto en la población sevillana homónima (Ruhstaller, 2009) o en la granadina Maracena (Jiménez Mata, 1990), puede pertenecer a uno de los tipos de topónimos representativos del antiguo Imperio Romano, un antropónimo formado a partir de un nombre de persona (Marsius, Marcius o Martius) más el sufijo - ana. En este sentido, es importante recordar la distinción entre Marchena y Marjena o Márgena porque para este segundo topónimo puede proponerse un origen distinto, relacionado con el árabe marŷa, que Albarracín et al (1986) traducen como "prado", y que en la toponimia de los Libros de Habices y los Libros de Apeo y Repartimientos del Valle de Lecrín puede localizarse en varios pagos que reciben la denominación del Marge, Marje o Marjen:

fol 9r Iten otra haça que esta en el Angostura que // cabe tres fanegas y media de tierra y alinda con // el marjen y con el monte y por la parte de abaxo / / con suerte del cura y sale a el camino rreal / / [Suerte de Lucas Hernández, Libro de Re-partimiento de Cozvíjar]

fol 12 Vna haça de riego en el pago de Marje Alcaçar de vn marja con seys azeytunos, linderos Açeheli e Doraygua [Habices de los Cautivos, Libro de Habices del Padul, 1501]

fol $3 r$ Ansy mismo en el dicho termino ay otra acequia de agua, que se saca del Rio de Concha, en el pago de que está abaxo de los Arcos de Canteron en el dicho río, esta agua riega el Pago que dicen el Marje (...) [Libro de Apeo y Repartimiento de Melegís, Espinar et al, 2006]

fol 217 (...) y dansele dos castaños en el marje, linde de Trance de ana lopez, viuda de dueñas (...) [Libro de Repartimiento de Nigüelas, Ferrer, 2000] 
También es de remarcar el hecho de que uno de los barrios que formaban parte de Dúrcal en el XVI y que aún da nombre a una de sus calles principales, se denomina, según distintas grafías, Andarro, Darro o Darron:

|fol 9v/ El dicho Lugar de Durcal esta dividido e apartado en seis varrios, que se llaman Marjena, Almohata alta, e baja, Celdelaque, e Balma, e Alanxa, e Andarro, e no ai mas de una iglesia donde se diga misa, que esta en el varrio / fol $10 \mathrm{r} /$ principal, aunque en el de Marjena ay una hermita.

El Libro de Habices de Dúrcal de 1501, por su parte, recoge hasta en veinte ocasiones el topónimo Abdarrof para nombrar a una rábita y un barrio:

Ifol 23/ Vn azeytuno en el pago Abdarrof, en tierra del açequia; $V n$ azeytuno en el pago de Margina, en tierra de Alazeraque (...)

Este topónimo, por otro lado, coincide con el del río aurífero de Granada, cuyo significado se relaciona con la palabra latina -aurum (García-Pulido, 2013):

\section{"Los Latinos lo llamaron Dauro, derivado de Dat-aurum, porque da oro, como afirma Luico Marineo, diriendo que, en su tiempo, se cogia mucho, y muy fino, y se coge cada dia." (Bermúdez de Pedraza, 1608)}

En la zona también está documentada la ocupación romana en Cozvijar, en Dúrcal y en el vecino pueblo de Cónchar. En Cozvijar, los trabajos de gestión integral del impacto arqueológico del tramo de autovía Alhendín-Dúrcal (Granada) realizados entre 1991 y 2000 descubrieron dos asentamientos rurales medievales andalusíes, uno de los cuales (La Fuente II) con ocupación en época bajoimperial romana (Ramos Millán y Osuna Vargas, 2001). En Dúrcal, en la otra orilla del río, se excavó una villae de cronología situada entre los siglox I y IV d-.C. (Burgos et al, 2006). También en las cercanías se encuentra el yacimiento arqueológico de Venta Hundida en donde se encuentran restos de tégulas asociados a un enterramiento.

Finalmente, es de reseñar que se conserva una denuncia al Gobernador Civil de Granada para labores de tierras auríferas junto al caserío de Cozvíjar de fecha 22 de mayo de 1923 (expediente 1421/30, Dirección General de Minas, Archivo Histórico Provincial de Granada) que extiende el rastro histórico del oro en la comarca.

En cuanto a las características de su trazado, los diseños de las conducciones principales de las acequias de Cozvijar-Marchena y de Nigüelas-Dúrcal son compatibles con la hipótesis de que hubiera explotaciones mineras romanas en Cozvíjar y Dúrcal. Hay que tener en cuenta que estos lavaderos auríferos explotaban oro aluvial que se encuentra en baja concentración en los conglomerados procedentes de la erosión de los materiales metamórficos paleozoicos de la Sierra (Martín Martín, 2000), lo que supone un gran esfuerzo en recursos y en trabajo y, en particular, una gran demanda de agua para el lavado (Sánchez Palencia et al, 1999).

En el primer caso, para derivar el agua desde el punto más cercano del río Dúrcal con la suficiente cota hasta la hipotética zona de vaciado, el trazado más sencillo y económico es la conducción directa hasta la zona de derrumbe, en dirección norte-sur, cortando las curvas de nivel. En el segundo caso, la canalización procedente del río Torrente llegaría directamente al punto de acometida de la mina (situado hipotéticamente en la prolongación de la acequia actual), sin tener que ajustarse a la configuración de las curvas de nivel. 
De acuerdo con este planteamiento, el desmonte derivado de la explotación minera aurífera de Cozvíjar sería posteriormente remodelado, abancalando los taludes para facilitar su uso agrícola. El canal que traía el agua a la mina pasó a ser la acequia principal de un sistema de regadío que estaba sometido desde el principio a la rigidez de un diseño inicial que sólo permitía poner en riego los pagos de Cozvíjar y el pago de Marchena. Es interesante reseñar que Cozvíjar, como otros pueblos del Valle de Lecrín, presenta el sufijo de terminación en -ar, que ha sido identificado como propio de topónimos preislámicos (Cagigas, 1932); en el caso concreto de Durkar, Jiménez Mata (1990) lo caracteriza como topónimo de posible origen no árabe. Es planteable, por tanto, que en un momento indeterminado se aportara riego a una entidad de población con una trayectoria histórica dilatada y a un pago con resonancias romanas (Marchena) que quedó incluido en el territorio de Dúrcal, de donde podría haber dependido la explotación minera (y, en consecuencia, la iniciativa de la construcción de la canalización). Con posterioridad al siglo XVII, y ante la existencia de tierras de la misma calidad agrológica que no habían podido entrar a formar parte del área irrigada debido a las restricciones del diseño original, se construyó una segunda acequia (la acequia de Los Llanos) para dominar las parcelas situadas en cota superiores, aunque su toma se situó aguas abajo de la acequia de Cozvíjar-Marchena.

En Dúrcal también se reconvirtió la zona de vaciado en un área agrícola aterrazada. Es posible también que la suavización del relieve provocada por el lavado aurífero favoreciera el trazado del camino principal que conectó el caserío con el río. En consecuencia, y siguiendo esta hipótesis, el sistema hidráulico de regadío Nigüelas-Dúrcal debió asumir igualmente las restricciones del diseño del sistema hidáulico minero original que conducía el agua del río Torrente hasta el emplazamiento de la zona de lavado, cuya huella pudo quedar fosilizada en el nombre del barrio del Darro.

¿Cuándo se llevó a cabo la reutilización del sistema? No lo sabemos. Tenemos, no obstante, constancia documental de que ambos sistemas hidráulicos estaban en funcionamiento en época nazarí y también deducimos que el poder real tuvo alguna intervención notable en el transcurso de su evolución histórica

En este contexto: ¿qué explicación cabe encontrar a la acequia de Márgena? Esta acequia, que parece converger, como hemos apuntado, en la misma zona del Darro de Dúrcal, riega pagos situados debajo del pueblo. En este sentido, accede a terrenos ubicados al final del recorrido de la acequia de Nigüelas-Dúrcal que, tras la reorientación de su finalidad original minera a uso agrícola, podrían haber contado con agua en precario. De este modo, el sistema hidráulico de la acequia de Márgena pudo responder exclusivamente a factores de diseño agronómicos al no estar sometido a las restricciones impuestas por un sistema preexistente, más allá de la delimitación del área con necesidades de regadío. Una vez en funcionamiento los dos sistemas, el de Nigüelas-Dúrcal pudo ajustar su dimensión, marcando el punto final de la acequia principal y abandonando el resto del antiguo canal.

Una última cuestión a interpretar es el emplazamiento de la presa de la acequia de Márgena, aguas arriba de la acequia de Cozvíjar-Marchena (que, de acuerdo con esta hipótesis, ha de haber sido situada con anterioridad), lo que puede ser explicable ante la necesidad topográfica de disponer de cota suficiente para acceder a las tierras que se tenía intención de regar. En tal caso, esta imposición topográfica obligaría a llegar a algún tipo de acuerdo con los regantes de la acequia de Cozvijar-Marchena. 
La hipótesis expuesta pretende contribuir a la interpretación de la lógica original y evolutiva de dos sistemas de regadío concretos: la acequia de Cozvíjar-Marchena y la acequia de Nigüelas-Dúrcal. No todos los sistemas hidráulicos del Valle de Lecrín de Granada responden a este planteamiento: en la mayor parte de ellos, de hecho, se deduce una lógica orientada desde el origen al regadío. En el caso de los sistemas hidráulicos estudiados en este trabajo, los diseños de la acequia de Márgena y el de la acequia de Los Llanos son coherentes con un propósito inicial de utilizar el caudal para regadío. Pero en el caso de las conducciones principales de los sistemas hidráulicos de Cozvíjar-Marchena y de NigüelasDúrcal, la hipótesis alternativa de que su datación es muy anterior y que finalidad inicial está vinculada a la explotación aurífera hidráulica se adecua a las características de su diseño y a los rasgos geográficos e históricos de su contexto. Estas conducciones iniciales serían objeto en una fecha indeterminada de una reorientación funcional que dio lugar a dos sistemas hidráulicos históricos que aún permanecen en activo.

\section{Agradecimientos}

A Javier Venegas Troncoso por su ayuda en la creación del SIG y en el tratamiento de la información territorial. A Carmen Trillo San José por la lectura crítica del manuscrito y por sus sugerencias.

\section{Referencias}

Albarracín Navarro, J.; Espinar Moreno, M.; Martínez Ruiz, J.; Ruiz Pérez, R. (1986): El Marquesado del Cenete: historia, toponimia y onomástica, según documentos árabes inéditos, Universidad de Granada, Granada.

Alfaro, P.; Galindo-Zaldívar, J.; Jabaloy, A.; López Garrido, A.C.; Sanz de Galdeano.C. (2001): Evidence for the activity and paleoseismicity of the Padul fault (Betic cordillrea, southern Spain), Acta Geologica Hispanica, 36: 283-295.

Bermúdez de Pedraza, F. (1608): Antigüedad y excelencias de Granada, Madrid.

Burgos Juárez, A.; Puerta Torralbo, D.; Cabrera Jiménez, E.; Pérez Bareas, C.; Toro, M. (2006): Informe preliminar de la intervención arqueológica de urgencia en la villa romana de "Los Lavaderos" de Dúrcal (Granada), Unidad de Actuación 8, Anuario Arqueológico de Andalucia, 2003, 1: 511-517.

Espinar Moreno, M.; González Martín, C.; de la Higuera Rodríguez, A.; Gómez Noguera, C. (2006): El Valle. Libros de Apeo y Repartimiento de Melegís y Restábal, Ayuntamiento de El Valle, Granada.

Ferrer, M. (2000): Libro de Apeo y Repartimiento de Suertes de Nigüelas, 1572, Ayuntamiento de Nigüelas.

García Pérez, J.F. (2011): Territorio y poblamiento medieval en el Valle de Lecrín. La alquería de Padul, Editorial Alhulia, Granada.

García Pérez, J.F. (2013): Paisajes históricos del área norte del Valle de Lecrín de la época nazaría a la conquista castellana, Tesis doctoral, Granada. 
García Pérez, J.F. (2013): Transformación de la práctica agrícola nazarí después de la conquista castellana en el contexto del Valle de Lecrín, en Jiménez Puertas, Miguel (ed.), El paisaje y el análisis del territorio. Reflexiones sobre el sur de al-Andalus, Granada, pp. 87-110.

García-Pulido, L.J. (2013): El territorio de la Alhambra. Evolución de un paisaje cultural remarcable, Universidad de Granada, Granada.

Jiménez Mata, M.C. (1990): La Granada islámica, Universidad de Granada - Diputación Provincial de Granada, Granada

Malpica Cuello, A. (1996): Poblamiento y castillos en Granada, El Legado Andalusí - Lunwerg editores, Barcelona.

Malpica Cuello, A. (2014): Las últimas tierras de Al-Andalus. Paisaje y poblamiento del reino nazarí de Granada, Universidad de Granada, Granada.

Martín Martín, A. (2000): Geología e historia del oro de Granada, Boletín Geológico y Minero, 111: 47-59.

Padilla Mellado, L.; Espinar Moreno, M. (2007): Arquitectura defensiva del Valle de Lecrín, Granada.

Padilla Mellado, L. (2010): Los habices de las iglesias del Valle de Lecrín. Historia y Arqueología, Tesis Doctoral,. Universidad de Granada, Granada.

Pedregosa Megías, R. (2011): La Torre de Márgena o Marchena, Dúrcal (Granada): una torre de alquería y su albacar", Antiquitas, 23: 293-302.

Ramos Millásn, A.; Osuna Vargas, M.M. (2001): La gestión del impacto arqueológico en carreteras. Un ejemplo andaluz en la autovía Alhendin-Dúrcal (Granada), Arkaion, S.C.A., Granada.

Ruhstaller, S. (2009): De toponimia latina. El nombre de lugar Marchena, en: Actas de las XIII Jornadas sobre Historia de Marchena. Nombres y signos, Ayuntamiento de Marchena, Sevilla, pp.: 11-19.

Sáenz de Galdeano, C.; López-Garrido, A.C. (2001): Estructura y tectónica activa del Valle de Lecrín (Granada), Geogaceta, 30: 187-190.

Sáenz de Galdeano, C.; Peláez Montilla, J.A.; López Garrido, A.C. (2001): La cuenca de Granada. Estructura, tectónica activa, sismicidad geomorfología y dataciones existentes, Universidad de Granada, Granada

Sánchez Palencia, F.J.; Fernández-Posse, M.D.; Fernández Manzano, J.; Orejas, Al. (1999): La zona arqueológica de Las Médulas, Instituto de Estudios Bercianos, León.

Trillo San José, C. (1994): La Alpujarra antes y después de la conquista castellana, Universidad de Granada, Granada.

Trillo San José, C. (2004): Agua: tierra y hombres en Al-Andalus. La dimensión agrícola del mundo nazarí, Editorial Ajbar, Granada. 
Villegas Molina, F. (1972): El Valle de Lecrín. Estudio Geográfico, Instituto de Geografía Aplicada del Patronato Alonso de Herrera, Granada. 